\title{
A 45-year-old woman referred for an independent medical evaluation by her insurer
}

\author{
Jason W. Busse DC PhD, Sturla E. Bruun-Meyer MBBCh MRCPsych(UK), Shanil Ebrahim PhD, Regina Kunz MD MSC
}

See related commentary, www.cmaj.ca/lookup/doi/10.1503/cmaj.131509

An insurer has requested that you conduct an independent medical evaluation for a 45-yearold woman, focusing on her ability to engage in rehabilitation efforts with the goal of returning to work. Her medical file mentions a predisability history of anxiety, as well as eight years of alcohol and oxycodone abuse. The patient was abstinent from alcohol for six years until one year ago, when she began drinking again. She left work three months later because of anxiety and alcohol abuse. Rehabilitation began six months ago, but her adherence has been limited. Her physician has advised that she is unable to engage in rehabilitation and that setting return-to-work timelines would cause deleterious stress.

\section{What is your role as an independent medical evaluator?}

Independent medical evaluations (IMEs) are a common form of assessment requested by third parties (e.g., insurers or attorneys) to determine an examinee's functional ability, to optimize treatment or to contribute to decisions regarding compensation. Treating physicians should be advocates for their patients; however, this legitimate role is likely to interfere with their ability to provide objective assessment in the face of contentious issues with insurers. As such, the IME should be performed by a physician who does not have an existing relationship with the patient.

An IME may represent an impartial assessment of the examinee's level of functioning, diagnosis or prognosis, or it may inform recommendations for treatment. The impartiality of an independent medical evaluator may, however, be compromised by the referring parties' vested interest in the outcome. ${ }^{1}$ Specifically, physicians are well compensated for performing IMEs and may compromise future referrals if they side against the referral source. ${ }^{2}$ Evaluators should be aware of this conflict and strive for impartiality.
In North America, physicians receive little training in conducting IMEs, and there are no binding regulations guiding the conduct or reporting of such evaluations; however, educational resources are available (Box 1). Although independent medical evaluators should undertake a systematic approach consistent with current guidelines, ${ }^{3-5}$ implement procedures to guard against legal challenges and formally address evidence of symptom exaggeration, the best approach to these issues remains uncertain. We performed a literature review to inform the suggestions presented in this article, which yielded only low-quality evidence to guide independent medical evaluators. (A list of the references identified in the literature review appears in Appendix 1, available at www.cmaj.ca /lookup/suppl/doi:10.1503/cmaj.130863/-/DC1.) Unless otherwise specified, our suggestions are based on expert opinion. Appendix 2 (available at www.cmaj.ca/lookup/suppl/doi:10.1503/cmaj $.130863 /-/ D C 1)$ compares the recommendations of Canadian guidelines ${ }^{3-5}$ with the findings of our review.

\section{What steps should you undertake before assessing the patient?}

To become familiar with the case and to allow identification of inconsistencies between the examinee's statements and information from other clinicians, an independent medical evaluator should review the patient's medical records pertaining to the referral before the assessment and, in any

Box 1: Educational resources for independent medical evaluators

- Canadian Society of Medical Evaluators: www.csme.org

- University of Montreal, Program in Insurance Medicine and Medicolegal Expertise: www.mae.umontreal.ca

- American Academy of Disability Evaluating Physicians: www.aadep.org

- American Board of Disability Analysts: www.americandisability.org

- American Board of Independent Medical Examiners: www.abime.org 
reports subsequently prepared, should note the documents reviewed. The referral source is responsible for providing all relevant medical records.

On the basis of our literature review, we suggest that evaluators use validated questionnaires to measure function or the effects of unhelpful beliefs (e.g., fear-avoidant behaviours) and that they ask examinees to complete, and administrative staff to score, any such instruments before the IME. Evaluators must have the required training to interpret the results of any instruments that they administer.

\section{How does an IME differ from a typical medical visit for this patient?}

An IME takes place in the context of an adversarial medicolegal system and typically requires two to four hours to complete. An IME that shows no disability jeopardizes continued wage replacement benefits for the patient; as such, examinees, who must attend the IME or risk losing their benefits, often approach the evaluation with caution or even hostility. Evaluators must strive to establish a rapport and avoid any impression of being disrespectful.

The evaluator should explain the purpose of the IME, identify the requesting party who will receive the report and explain that there will be no subsequent contact between the evaluator and the examinee. We suggest that the patient be asked to complete a signed consent form, acknowledging the nature and purpose of the assessment, allowing the release of information and giving approval for the evaluator to perform the IME.

On the basis of our review, we suggest that evaluators deny examinees' requests to record IME sessions, as this may draw attention to the recording and away from the assessment. An examinee may also request that an observer (e.g., a lawyer or the person's spouse) be present for the assessment, but we advise that assessors generally refuse such requests. Although an observer may make the examinee feel more comfortable and may provide additional information, involvement of an observer may compromise the efficiency and potentially the accuracy of the assessment. If, for some reason, an evaluator decides not to follow this general rule, the presence of observers and any contributions they make should be noted.

\section{What factors on history-taking are important in assessing the patient?}

Obtaining a detailed biopsychosocial history is important. Understanding the examinee's current situation involves determining any pre-existing conditions and prior injuries, function before the disability and what the person believes contributed to the inability to maintain employment. The history should include the circumstances surrounding the injury or start of the illness; subsequent assessments, treatment and results; and efforts to return to work.

The examinee's perception of causal and perpetuating factors may provide insight into the relative contribution of medical and nonmedical issues and may thus direct further questioning (e.g., toward workplace or relationship issues). On the basis of our review, we suggest that evaluators address any inconsistencies between the written record and the examinee's historical report. A systematic review supports the concept of evaluators establishing examinees' perception of how their condition should be managed and their degree of hopefulness about recovery and return to work, as a worker's perceptions of his or her condition are associated with outcome. ${ }^{6}$

Upon questioning, you find that the patient has longstanding vulnerability to anxiety and associated alcohol abuse. Her return to alcohol use after six years of abstinence was precipitated by difficulty coping with the stress associated with a promotion at work. She has been given a prescription for zopiclone $7.5 \mathrm{mg}$ at bedtime, which she reports is effective. She says she was abstinent from alcohol for one year before your assessment and reports that her anxiety is minimal, so long as she is not working or engaged in efforts to resume employment. She is concerned that any attempts to return to work will trigger disabling symptoms of anxiety.

\section{Is there evidence of symptom exaggeration?}

In an observational study of 508 examinees with chronic pain and financial incentive, the prevalence of malingering ranged from $20 \%$ to $50 \%$, depending on the diagnostic system used. ${ }^{7} \mathrm{~A}$ systematic review showed that among examinees attending for neurocognitive assessment, the estimate of malingering was $40 \%{ }^{8}$ The diagnosis of malingering places evaluators in the difficult position of having to establish intent. Therefore, we prefer the less value-laden term "symptom exaggeration." We suggest that evaluators assess the extent of symptom exaggeration on the basis of observed versus reported abilities, the findings of other providers, self-reported history that is discrepant with documented history and administration of validated tests.

Commonly used tests for assessment of effort for examinees attending for neurocognitive assessment are the Test of Memory Malingering ${ }^{9}$ and the Structured Interview of Reported Symptoms $;{ }^{10}$ however, beyond-chance scores are infrequent, which makes it likely that symptom exaggeration will be underestimated. ${ }^{11}$ As with physical complaints, rather than diagnosing symp- 
tom exaggeration on the basis of a single test, we suggest that evaluators incorporate both testing and clinical findings. (See Appendix 3, available at www.cmaj.ca/lookup/suppl/doi:10.1503/cmaj .130863/-/DC1 for a list of some available tests of symptom exaggeration.)

The patient completes both the Test of Memory Malingering and the Structured Interview of Reported Symptoms. Neither the results of these tests nor your findings on clinical observation suggest exaggeration of symptoms.

\section{Do any objective findings support the patient's complaints?}

Insurers often wish to know if objective findings support the examinee's complaints. The physical examination should focus on objective tests. Motivation can influence subjective testing; for example, an observational study reported that among examinees with disabling chronic low-back pain, range of motion was not associated with functional ability. ${ }^{12}$ If further assessment by a specialist in another medical discipline is required, the report should include recommendations to that effect.

For examinees presenting with mental illness, the IME should be tailored to the presenting complaint or complaints but should also include a full evaluation of mental status, including an assessment of presentation, cooperation, mood and affect, as well as thought form, content and perception, recall, insight and judgment. Although IME referral sources may still require that the findings of a mental health assessment be summarized according to the Diagnostic and Statistical Manual of Mental Disorders, fourth edition (DSM-IV), there is evidence to suggest that the Global Assessment of Functioning Scale (axis 5) is neither reliable nor valid, ${ }^{13}$ and this score is not in use in the fifth edition of the DSM (DSM-5).

The patient is appropriately dressed and groomed, is of normal weight, appears her stated age and is cooperative, with appropriate behaviour, good eye contact and normal emotional energy. She does not appear depressed or anxious and is cognitively intact: her insight, judgment, concentration and memory are all normal. From the available information, she would fit the DSM-5 criteria for generalized anxiety disorder with panic symptoms at times, as well as alcohol abuse in remission.

\section{What components should appear in the report?}

The written report of an IME summarizes the evaluator's review of previous records, the interview with the patient, findings of the examination and conclusions. On the basis of our literature review, we suggest that evaluators routinely include a disclaimer acknowledging the limitations of a single examination and advise that the report is based on available information and that new findings may alter conclusions. Independent medical reports are directed to nonmedical readers, and evaluators should therefore use lay language; if medical terms are necessary, they must be explained. The report should avoid unsupported conclusions, emotional statements or comments that may be derogatory to the examinee or treating providers; one reason is that the report may be admitted into evidence at trials and administrative hearings.

Responding to a referral source's request for advice regarding whether an examinee can return to work requires expertise in vocational rehabilitation, as medical restrictions do not correlate well with the ability to work. The Ontario Medical Association has recommended that unless an evaluator possesses the required expertise and information, he or she should not comment on the examinee's ability to resume employment, restricting comments to medical restrictions (what the examinee should not do) and limitations (what the examinee cannot do). ${ }^{14}$

\section{The case revisited}

You are aware that the insurer would like the report to conclude that it remains realistic for the patient to return to work, and it is in your interest to encourage further referrals from the insurer. The patient is frightened of returning to work, and although she is not limited (from a psychiatric perspective) from re-engaging in vocational reintegration, her fear is likely to escalate once the reintegration approaches. Her physician's reluctance regarding rehabilitation and setting return-to-work targets is therefore understandable. However, it may not be in the examinee's best interests, given the findings of a systematic review showing that return to work is associated with improvements in health status. ${ }^{15}$

Staying objective in the face of your conflict of interest is challenging, but you think that with further rehabilitation and a gradual reintroduction to work-related tasks, the patient can resume employment. Your recommendation therefore reflects this conclusion.

\section{References}

1. Ebrahim S, Sava H, Kunz R, et al. Ethics and legalities associated with independent medical evaluations. CMAJ 2014; 186:248-9.

2. Spencer RF. Are independent medical examiners truly independent? Pain Physician 2010;13:92-3.

3. Canadian Society of Medical Examiners report writing guidelines for psychiatric impairments. Toronto: Canadian Society of Medical Evaluators; 2004. Available: http://c.ymcdn.com/sites /www.csme.org/resource/resmgr/imported/Report\%20Writing\%20 Guidelines\%20for\%20Psychiatric\%20Impairments\%20\%200504 .pdf (accessed 2014 Sept. 2). 
4. Third party reports (policy no.: \#2-12). Toronto: College of Physicians and Surgeons of Ontario; 2012. Available: www.cpso.on .ca/policies/policies/default.aspx?ID=1658 (accessed 2013 Mar. 16).

5. Appendix A: Guidelines and detailed outline for medico-legal reports. In: The medico-legal report, 2008. Toronto: MedicoLegal Society of Toronto; 2008.

6. Mondloch MV, Cole DC, Frank JW. Does how you do depend on how you think you'll do? A systematic review of the evidence for a relation between patients' recovery expectations and health outcomes. CMAJ 2001;165:174-9.

7. Greve KW, Ord JS, Bianchini KJ, et al. Prevalence of malingering in examinees with chronic pain referred for psychologic evaluation in a medico-legal context. Arch Phys Med Rehabil 2009;90:1117-26.

8. Jasinski LJ, Berry DT, Shandera AL, et al. Use of the Wechsler Adult Intelligence Scale Digit Span subtest for malingering detection: a meta-analytic review. J Clin Exp Neuropsychol 2011; 33:300-14.

9. Tombaugh T. Test of memory malingering manual. New York: MultiHealth Systems; 1996.

10. Rogers R, Bagby RM, Dickens SE. SIRS: structured interview of reported symptoms: professional manual. Odessa (FL): Psychological Assessment Resources; 1992.

11. Slick DJ, Sherman EM, Iverson GL. Diagnostic criteria for malingered neurocognitive dysfunction: proposed standards for clinical practice and research. Clin Neuropsychol 1999;13:545-61.

12. Parks KA, Crichton KS, Goldford RJ, et al. A comparison of lumbar range of motion and functional ability scores in patients with low back pain: assessment for range of motion validity. Spine (Phila Pa 1976) 2003;28:380-4.

13. Grootenboer EM, Giltay EJ, van der Lem R, et al. Reliability and validity of the Global Assessment of Functioning Scale in clinical outpatients with depressive disorders. J Eval Clin Pract 2012;18:502-7.

14. Medical Care and Practice Committee. Position in support of timely return to work programs and the role of the primary care physician [position paper]. Toronto: Ontario Medical Association; 1994.

15. Rueda S, Chambers L, Wilson M, et al. Association of returning to work with better health in working-aged adults: a systematic review. Am J Public Health 2012;102:541-56.

Competing interests: Jason Busse acts as a consultant to Prisma Health Canada, a private incorporated company funded by employers and insurers that consults on and manages long-term disability claims. Sturla Bruun-Meyer has previously conducted independent medical evaluations on behalf of numerous Canadian private disability insurers. Regina Kunz is the director of the Swiss Academy of Insurance Medicine at the University Hospital Basel, an organization funded in part by donations from public insurance companies and a consortium of private insurance companies. No competing interests declared by Shanil Ebrahim.
Affiliations: Michael G. DeGroote Institute for Pain Research and Care (Busse), Department of Anesthesia (Busse, Ebrahim) and Department of Clinical Epidemiology and Biostatistics (Busse, Ebrahim), McMaster University, Hamilton, Ont.; Faculty of Medicine (Bruun-Meyer), University of Toronto, Toronto, Ont.; Stanford Prevention Research Center, Department of Medicine (Ebrahim), Stanford University, Stanford, Calif.; Swiss Academy of Insurance Medicine, University Hospital Basel (Kunz), Basel, Switzerland

Contributors: Each author contributed substantially to conception and design of the article, revised it critically for important intellectual content, and gave final approval of the version to be published.

Acknowledgements: The authors thank Dr. Gordon Guyatt for his contribution to the conception, design and critical review of the manuscript and Rachel Couban for her support in developing the search strategy for the systematic review that informed the manuscript.

Jason Busse is funded by a New Investigator Award from the Canadian Institutes of Health Research and the Canadian Chiropractic Research Foundation. Shanil Ebrahim is supported by a Mitacs Elevate Postdoctoral Fellowship Award.

Decisions is a series that focuses on practical evidence-based approaches to common presentations in primary care. The articles address key decisions that a clinician may encounter during initial assessment. The information presented can usually be covered in a typical primary care appointment. Articles should be no longer than 650 words, may include one box, figure or table and should begin with a very brief description (75 words or less) of the clinical situation. The decisions addressed should be presented in the form of questions. A box providing helpful resources for the patient or physician is encouraged. 